\title{
SCOPE OF VHF PLASMA DEPOSITION FOR THIN-FILM SILICON SOLAR CELLS
}

\author{
H. Keppner, U. Kroll, P. Torres, J. Meier, D. Fischer, M. Goetz, R. Tscharner and A. Shah \\ Institut de Microtechnique (IMT), Rue A. L. Breguet 2, 2000 Neuchâtel, Switzerland \\ Tel.: ++41/38 233 349; Fax: ++41/38 233 201; e-mail: Keppner@ imt.unine.ch
}

\begin{abstract}
The world-wide attempts in obtaining thin-film crystalline silicon are reviewed. Based on literature published sofar, it appears that high-temperature manufacturing steps seem to be unavoidable for obtaining high conversion efficiencies of crystalline silicon based solar cells. High process temperatures are in contradiction for the use of low-cost substrates like e.g. glass or aluminium. Such substrates, however, are essential for obtaining low module manufacturing costs. The Very High Frequency Glow Discharge Process (VHF-GD) could have the potential to overcome the temperature - efficiency contradiction.
\end{abstract}

\section{INTRODUCTION}

Solar cells based on crystalline silicon wafers show high efficiencies, however, their cost reduction potential is aiready almost fully exploited using conventional techniques. Thin-film solar cell concepts, like amorphous silicon (a-Si:H), copper indium diselenide (CIS) and CdTe have still a good cost reduction potential due to large-area, low-temperature manufacturing. These technologies contain, however, at least one striking disadvantage, mainly due to too low efficiencies or problems with the reproducibility at the pilot production level. Furthermore, new aspects like short pay-back time in energy, in costs and in environmental investments for future cell manufacturing have to be seriously taken into account.

\section{THIN-FILM SILICON}

It makes sense to combine the advantages of the well-established wafer-based silicon technology and thinfilm technology in order to obtain thin-film crystalline silicon solar cells. The demands on this "magic" thin film silicon, looking at low-cost high efficiency solar cell manufacturing, can be expressed by the following catalogue:

1 Thin-film silicon must be condensed from the gas-, liquid- or the plasma-phase on a (foreign) substrate.

2 The substrate should be a (cheap) non-silicon material as e.g. glass, plastic or metal.

3 There should be no special requirements on the preorientation from the substrate to the growing film.

4 The process for deposition of thin-film silicon should be a low-temperature process $\left(\mathrm{T}<400^{\circ} \mathrm{C}\right)$.

5 The deposition rate of thin-film silicon must be high; hence total process time should be low.

6 The thickness of the films (including light-trapping) should be sufficient for absorbing the whole sun spectrum, whereas,

7 the diffusion / dritt length of thin-film silicon must be larger than the thickness of the cell.

8 It should have the potential for large-area module manufacturing.

\section{REVIEW OF THIN-FILM SILICON PROCESSES}

Such an ideal thin-film silicon which fulfills simultaneously all previous points is sofar only a vision. No technological process is sofar at hand to produce such a material. Note that the points 6 and 7 include the demand for a high efficiency, whereas all other points refer to the demand for cost reduction.

Within the last years, several laboratories in the world have picked up the challenge to deposit thin-film silicon. Tab. 1 gives an overview of the most important contributions. A detailed analyse of Tab. 1 shows the following features:

- cell efficiencies significantly higher than $10 \%$ seem sofar exclusively be reserved for processes higher than $900^{\circ} \mathrm{C}$;

- a preorientation from the substrate is required or a wafer-type, self supporting substrate has to be applied;

- the a-Si:H/a-SiGe:H technology comes quite close to the ideal case ( 8 points). However, it is questionable whether much higher efficiencies can be obtained in future. It is the only non-crystalline silicon cell included for comparison;

- the process time for all cells is very long except the wafer-type based ribbon silicon cell or the hot wire process (still no cells presented sofar);

- the Micromorph cell contains a stable microcrystalline cell with still a promising potential for obtaining higher efficiencies at low process temperature.

The Micromorph tandem cell is the first thin-film silicon cell that consists of an amorphous silicon cell and an entirely microcrystalline $p-i-n$ cell. It can thus be considered as the desired combination of the advantages of amorphous and crystalline silicon at low temperatures.. Looking at the status of Micromorph cell in Tab. 1, one must concede, however, that the comparison to other thin-film silicon cell approaches that are not tandem cells, might not be fair. All tandem concepts containing cells with two different gap energies can make better use of 


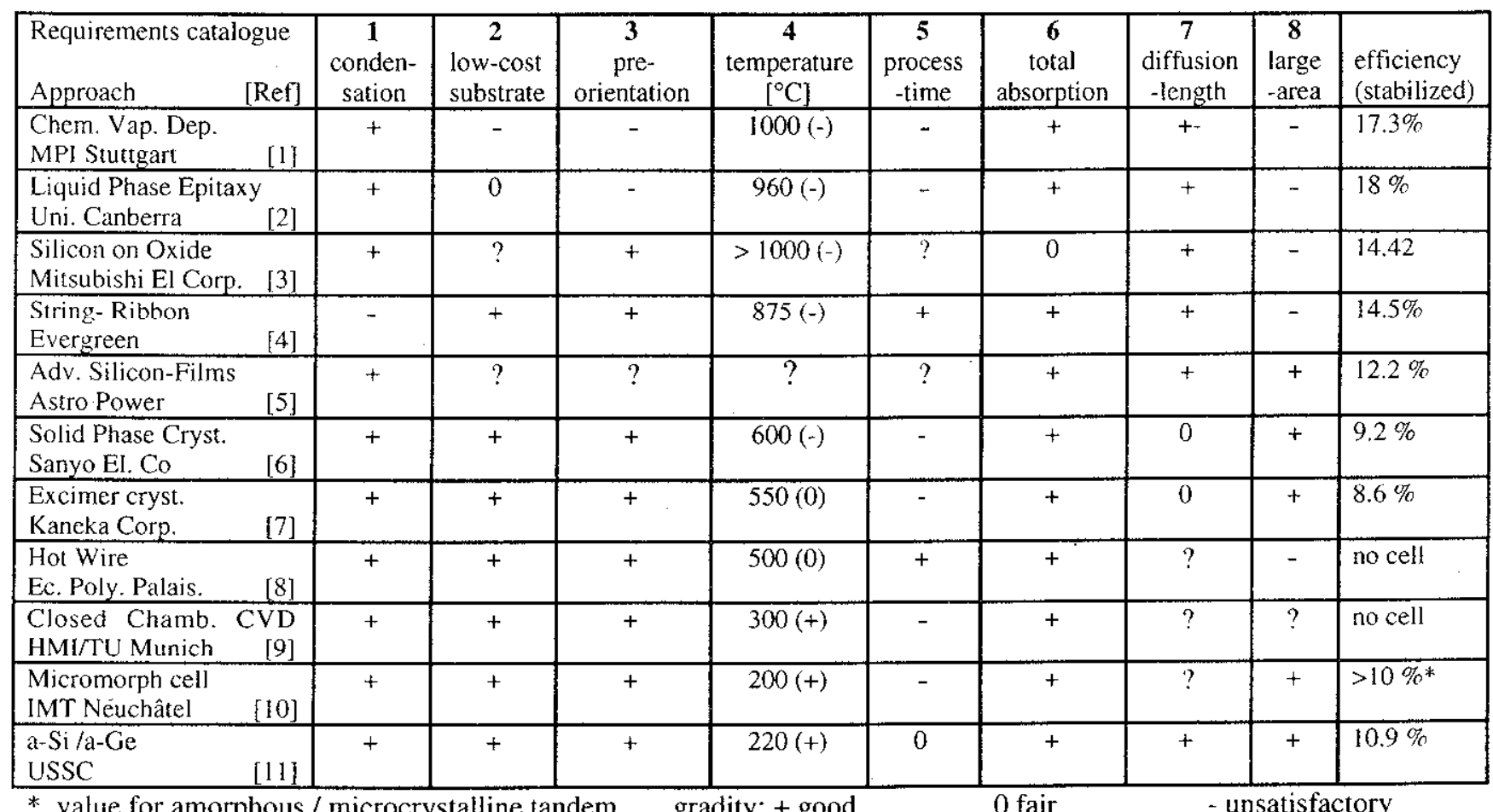

* value for amorphous / microcrystalline tandem

gradity: + good

0 fair

- unsatisfactory

Tab. 1. Different approaches for obtaining thin-film silicon. The approaches are judged looking at the eight point catalogue presented above. The process temperature classification was considered to be positive if glass substrates can be used.

the solar spectrum. In fact, the $\mu \mathrm{c}-\mathrm{Si}: \mathrm{H}$ bottom cell has an energy gap of about $1 \mathrm{eV}$, whereas the gap of amorphous top cell is about $1.7 \mathrm{eV}$. The Micromorph cell in Tab. 1 must be more seen under the aspect of combining amorphous silicon and crystalline silicon processing at low temperature. The a-Si:H technology contributes thereby the feasibility of serial connections where the transparent glass substrate is simultaneously one part of the encapsulation.

\section{LOW-TEMPERATURE GROWTH MODEL OF SILICON}

The following model is proposed understand the growth mechanism of crystalline silicon at low temperatures. The model is based on two necessary conditions for Si-radicals to contribute to epitaxial growth:

(i) The surface mobility must be high enough so that the radicals can first move that stick at a crystal site.

(ii) The energy impinging particles on the growth zone must not exceed the threshold energy for defect formation.

The model is briefly sketched out in Fig. 1. It was shown experimentally by Torres et al. [11] that epitaxial growth of highly boron doped monocrystalline silicon at temperatures as low as $170^{\circ} \mathrm{C}$ is possible.

If no orientation from the substrate is given, as sketched in Fig. 2, it is claimed that under the conditions (i) and (ii) high quality $\mu \mathrm{c}-\mathrm{Si}: H$ can be obtained at low temperatures. As a particularity of this material, columnar growth with a high crystalline fraction is observed [10].

Condition (i) is guaranteed for high substrate temperatures that are used in conventional CVD processes, but high temperature is unwanted. Plasma processes, in general, offer the possibility of low temperature dissociation but condition (ii) is generally not fulfilled using standard conditions of DC PECVD or at a plasma excitation frequency of $13.56 \mathrm{MHz}$

Plasma processes have the advantage that dissociation of silane occurs at low substrate temperatures due to electron impact. However, because of the sheath potential ions are accelerated between the plasma edge and the substrate. In general lattice damage due to ion impact is caused. Neutrals furthermore undergo the charge exchange reaction (1); they can hence also cause lattice defects:

ion (fast) + atom (slow) -> atom (fast) + ion (slow)

Veprek et al. [13] found that the threshold energy $E_{\text {th }}$ for defect formation in a $\mathrm{c}$-Si lattice due to hydrogen impact is $117 \mathrm{eV}$, for silicon it is about $16 \mathrm{eV}$, whereas Dutta et al. [14] estimated the peak ion energy in function of the plasma excitation frequency (Fig. 3). 

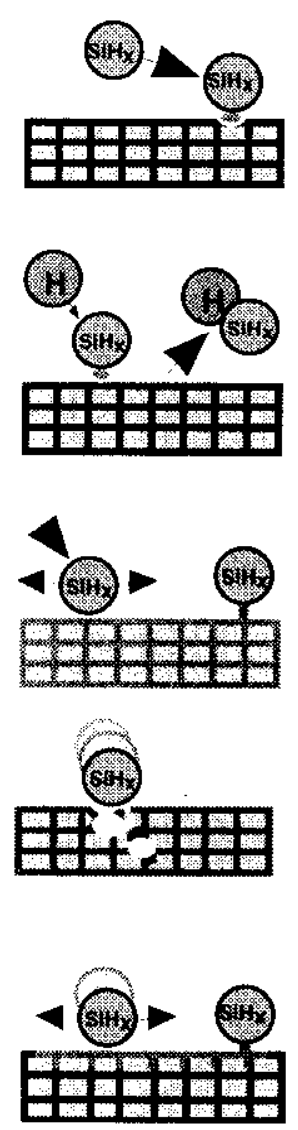

Low substrate temperature:

A radical reacts immediately at any place, i.e. a non-crystal site.

No epitaxial growth occurs.

Atomic hydrogen etching can remove a radical from a noncrystal site.

The "error" in crystal growth can be corrected.

At high substrate temperature $\left(>800^{\circ} \mathrm{C}\right)$ surface diffusion of radicals is activated.

They react at a crystal site. CVD case

Epitaxyial growth occurs.

Too high kinetic energy of the radical cause lattice defects. The information for epitaxial growth is lost. General case for PECDV for DC or $13.56 \mathrm{MHz}$ : No epitaxy.

The energy of the radicals is high but not sufficient for defect formation, "virtual surface heating" happens. Surface diffusion is activated.

PECVD at VHF-GD conditions. Epitaxial growth occurs.

Fig. 1: Schematical sketch of low-temperature epitaxial growth on $\mathrm{C}-\mathrm{Si}$ by means of the VHF-GD process. TEM picture from previous work proves epitaxy at $170^{\circ} \mathrm{C}$ [12]

Using a Very High Frequency Glow-Discharge plasma at an excitation frequency of $70 \mathrm{MHz}$ or higher, peak ion energies as low as $14 \mathrm{eV}$ can be estimated, i.e. lower than the threshold energy $E_{\text {th }}$ for the Si impact. At lower excitation frequencies, e.g. $13.56 \mathrm{MHz}$, however, values as high as $45 \mathrm{eV}$ are typically observed.

lons that are accelerated in the sheath by the sheath potential can loose energy due to collision with other particles (thermalization). The efficiency of thermalization of a particle of the mass $M$ that strikes a particle of the mass $m$ is given by the energy transfer function (2):

$$
\mathrm{T}=\frac{\mathrm{M} \cdot \mathrm{m}}{(\mathrm{M}+\mathrm{m})^{2}} . \quad \mathrm{T}=\mathrm{T}_{\max } \text { if } \mathrm{M}=\mathrm{m}
$$

According to Somekh [14] the total number of collisions is a measure of thermalization. In the case of $\mu \mathrm{c}-\mathrm{Si}: \mathrm{H}$ deposition conditions, a strongly hydrogen diluted $\mathrm{SiH}_{4}$ plasma $\left(2 \% \mathrm{SiH}_{4}\right.$ in $\left.\mathrm{H}_{2}\right)$ is applied. In this

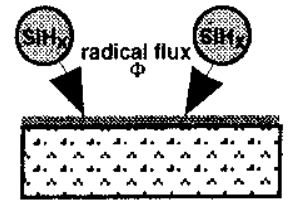

Due to the lack of forces that lead to oriented growth an amorphous silicon layer is formed.

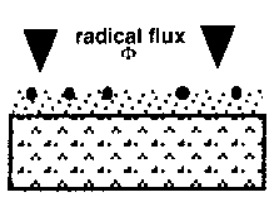

Under favourable conditions, by chance, some tiny crystalline seeds are formed.

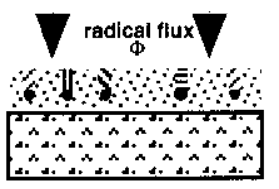

If the ion energy is too large, crystal growth and crystal damage-formation are balanced: only small crystals embedded in an amorphous matrix are formed.

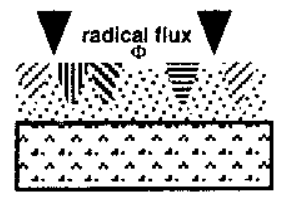

If the substrate temperature is high enough, surface diffusion within the crystal area favours crystalline growth.

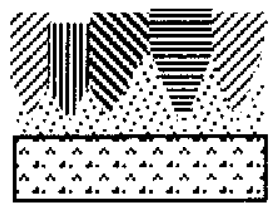

Under VHF-GD conditions the surface mobility of radicals is high and the defect formation rate is reduced. Columnar growth with a high crystalline volume fraction occurs [10].

Fig. 2: Schematical sketch of the columnar growth of solar-grade $\mu \mathrm{c}$-Si:H by means of the VHF-GD process.

case, only the collision of silicon radicals with similar radicals contribute to thermalization: if a fast $\mathrm{Si}$-ion strikes a $\mathrm{H}$-atom, only $6 \%$ of the energy is transferred, hence no thermalization occurs. For hydrogen ions is, on one hand, the threshold energy for defect formation very high, on the other hand perfect thermalization within the sheath can be assumed. Hence defect-formation due to hydrogen impact is assumed to be negligible.

Tab. 2 compares the mean free path $\mathrm{I}_{\mathrm{H}}$ and $\mathrm{ISi}_{\mathrm{Si}}$ with the sheath thickness $d$; the number of collisions n $\mathrm{Si}$ within the sheath can be seen as a measure for the degree of thermalization of $\mathrm{Si}$ radicals.

For hydrogen diluted silane $13.56 \mathrm{MHz}$ plasmas it can be concluded from Tab. 2 that ion energies higher than the threshold energy for defect formation are found. Furthermore, no thermalization in the sheath occurs. For a $70 \mathrm{MHz}$ plasma, e.g. no thermalization occurs as well, but the energy of the $\mathrm{Si}$ ions is less than the threshold energy for defect formation. The VHF-GD process at 70 $\mathrm{MHz}$ excitation frequency (and higher) fulfills hence the 
condition (ii); it plays by that, à priori, an imprtant role in low defect (crystalline) semiconductor manifacturing.

The condition (i) is also fulfilled; Heintze et al. [17] showed experimentally that at higher excitation frequencies the ion flux to the electrodes is increased. The latter one gives rise to an enhanced surface diffusion, even at low substrate temperature.

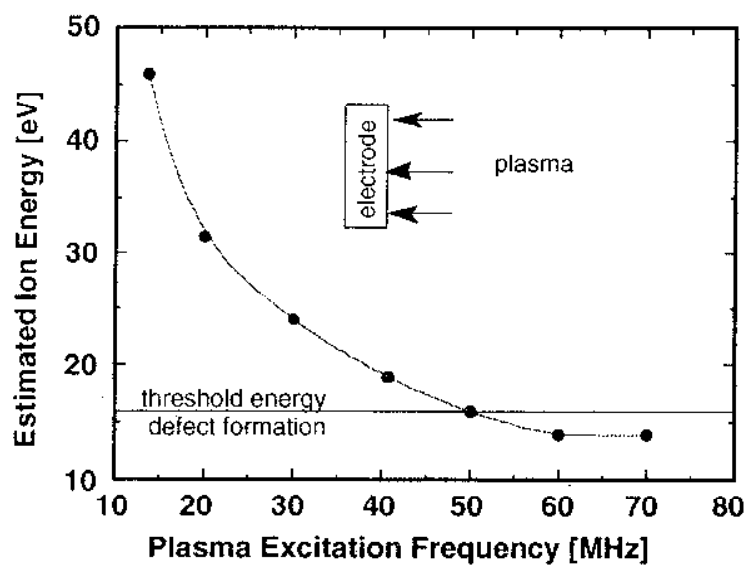

Fig. 3. Estimated peak ion energies in function of the frequency for $\mathrm{SiH}_{4}$ plasmas. According to Dutta et al. [14].

\begin{tabular}{|c|c|c|c|c|c|c|c|}
\hline $\begin{array}{c}f \\
\mathrm{MHz}\end{array}$ & $\begin{array}{c}\mathrm{E}^{*} \\
\mathrm{eV}\end{array}$ & $\begin{array}{c}\mathrm{d}^{\star \star} \\
\mathrm{mm}\end{array}$ & $\begin{array}{c}\mathrm{IH}_{\mathrm{H}} \\
\mathrm{mm}\end{array}$ & $\begin{array}{c}\text { ISi } \\
\mathrm{mm}\end{array}$ & $\mathrm{nH}$ & $\mathrm{nSi}$ & rem. \\
\hline 13.5 & 45 & 4.4 & 0.6 & 30 & 7.3 & 0 & $\mathrm{E}(\mathrm{Si})>\mathrm{E}_{\text {th }}$ \\
\hline 70 & 14 & 1.4 & 0.6 & 30 & 2.3 & 0 & $\mathrm{E}(\mathrm{Si})<\mathrm{E}_{\text {th }}$ \\
\hline
\end{tabular}
[16]

Tab. 2: Effect of thermalization in a hydrogen diluted $\mathrm{SiH}_{4}$ plasma used for the deposition of microcrystalline silicon.

\section{CONCLUSIONS}

We assume that in a strongly hydrogen diluted silane VHF plasma, as used for $\mu \mathrm{c}$-Si:H deposition, silicon ion impact can not cause lattice damage. The increased ion flux gives rise to an enhanced surface diffusion of radicals in a more pronounced way as for a $13.56 \mathrm{MHz}$ plasma. These two conditions (i) and (ii) formulated by our model are the requirements for the growth of crystals from localized seeds. The ensemble of all crystals together have by that the possibility to form high quality columnar $\mu \mathrm{c}-\mathrm{Si}: \mathrm{H}$, as implemented in the micromorph cell.

It is expected that further progress in low-temperature thin-film silicon solar cell technology can be achieved that fulfills the eight requirements presented above. Further improvements of the deposition rate and of the cell performance are still needed.

\section{ACKNOWLEDGEMENTS}

This work was supported by the Swiss Federal Office of Energy (BEW /OFEN) under Grant REN (93)032.

\section{REFERENCES}

[1] R.Brendel, M.Hirsch, M.Stemmer, U.Rau, and J.H.Werner, Appl. Phys. Lett. 66 (1995) p. 1261.

[2] K.J.Weber, A.Stevens, and A.W.Blakers, $13^{\text {th }}$ ECPVC Nice, (1995), p. 1590.

[3] M.Deguchi, Y.Kawama, Y.Matsuno, Y.Nishimoto, H.Morikawa, S.Arimoto, H.Kumabe and T.Murotani, Proc. 1st WCPEC, Hawail (1994), p. 1287.

[4] D.Ruby, W.Wilbanks, C.Fleddermann, and J.Hanoka, $13^{\text {th }}$ ECPVC Nice, (1995) p. 1412.

[5] R.B.Hall, A.M..Barnett, J.E.Cotter, D.H.Ford, A.E.Ingram, and J.A.Rand, to be publ. in Proc. of MRS Conf. spring meeting 1996.

[6] T.Baba, M.Shima, T.Matsuyama, S.Tsuge, K. Wakisaka and S.Tsuda, $13^{\text {th }}$ ECPVC Nice, (1995), p. 1708.

[7] A. Nakajima, T.Suzuki, M.Yoshimi, K.Yamamoto, $13^{\text {th }}$ ECPVC Nice, (1995), p. 1550.

[8] A.R.Middaya, J.Guillet, J.Perrin, A.Lloret, E.Bourrée, $13^{\text {th }}$ ECPVC Nice, (1995), p. 1704.

[9] R.Krankenhagen, M.Schmidt, S.Kyonow, S.Grebner, W.Henrion, I.Sieber, and R.Schwarz, $13^{\text {th }}$ ECPVC Nice, (1995), p. 1700.

[10] J.Meier, P.Torres, R.Platz, S.Dubail, U.Kroll, J.A. Anna Selvan, N.Pellaton Vaucher, Ch.Hof, D.Fischer, H.Keppner, A.Shah, K.-D.Ufert P.Giannoulès, J.Koeler, to be publ. in Proc. of MRS Cont. spring meting 1996.

[11] USSC cell in Solar efficiency Tab. version 6, Progress in Photovoltaics 3(4) (1995), p. 231.

[12] P.Torres, R.Fückiger, J.Meier, H.Keppner, U.Kroll, V.Sklover and A. Shah, 13th ECPVC, p. 1638.

[13] S.Veprek, F-A.Sarott, S.Rampert, E.Taglauer, J. Vac. Sci Technol. A. 7 (4), (1989), p. 2614.

[14] J.Dutta, U.Kroll, P.Chabloz, and A.Shah, J. Appl. Phys. 72 (7), (1992), p. 3220.

[15] R.Somekh, J.Vac.Sci.Technol. A2(3), (1984), p. 1285.

[16] U.Kroll, Ph.D thesis, Univ. Neuchâtel ISBN 389191-905-0 (1995).

[17] M.Heintze, R.Zeidlitz, G.H.Bauer, J.Phys.D: Appl. Phys. 26 (1993) p. 1781. 